\title{
Defect simulation during the building life cycle including initial phase
}

\author{
Dalibor Vytlačil ${ }^{1, *}$ \\ ${ }^{1}$ Czech Technical University in Prague, Faculty of Civil Engineering, Department of Engineering \\ Informatics, Thákurova 7, 16629 Prague, Czech Republic
}

\begin{abstract}
The paper presents the model for the description of the dynamic system concerning the defect simulation. The system includes the initial part of the life cycle where same amount of the rework has to be considered because of the low quality work. The second subsystem considers a division of the maintenance as planned and unplanned activities. The model connects these subsystems in one complex model that allows us to perform the simulations for investigating different problems. The example of the calculation of the key system parameters is presented in the paper. The resultant values demonstrate the importance of the maintenance but also the impact of the initial phase of the life cycle that has substantial influence on the amount of the defects in the early period.
\end{abstract}

\section{Introduction}

Amount of defects depends on the level of maintenance and also on the repair efforts that solve the ad-hoc problems. These activities are typical for in-service period, [1-2]. Additional source of defects is the erection period when same construction works are supplied with lower quality. These project activities are reworked during the project but also part of activities will influence the operational phase and they can be considered as the defects in the burn-in period, see [1] and Figure 1.

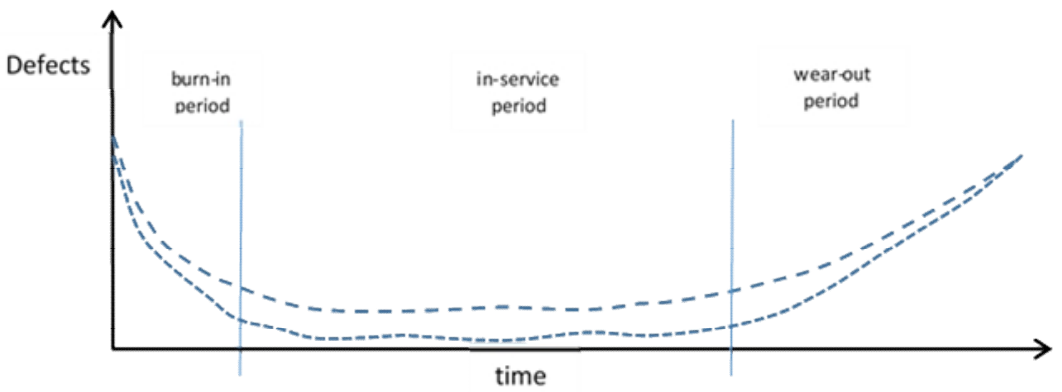

Fig. 1. Building defects during the life cycle.

\footnotetext{
*Corresponding author: vytlacil@,fsv.cvut.cz
} 
The purpose of the research is to develop the model that will cover the whole service period (the early service period and the late service period) and also the construction period.

\section{Method}

The dynamic model uses the system dynamics methodology. This methodology is described in many books, for example in [3-4]. In investigated problem the stock element represents the amount of defects that is represented as multiplication of the time and work needed for elimination of the defect. The unit can be man-day, man-month or man-year.

The flows elements change the values of the stock elements and typical unit is parameter value per time unit. The model for investigated problem is presented in Figure 1.

\section{Model description}

The model includes two subsystems that deal with different defect creation. The upper part of the model is the subsystem for the initial phase of the building life cycle, it means the time period of construction activities. This part uses different stocks for the description of the project activities. Project work is in the beginning. This stock is the amount of work that has to be done for building the designed structures. During the construction, activities are moved to Finished work stock but from this stock there are two flows representing the fact that same of them are performed with lower quality. These activities will be done once more, therefore Rework work stock is introduced in the model. All activities are moved to Ready work stock. The activities that are not well-performed in time are considered as defects and they will be reworked after the project schedule. The parameter elimination effort is the time for finishing activities. Quality coeff \% (quality coefficient) defines the ratio of low quality work.

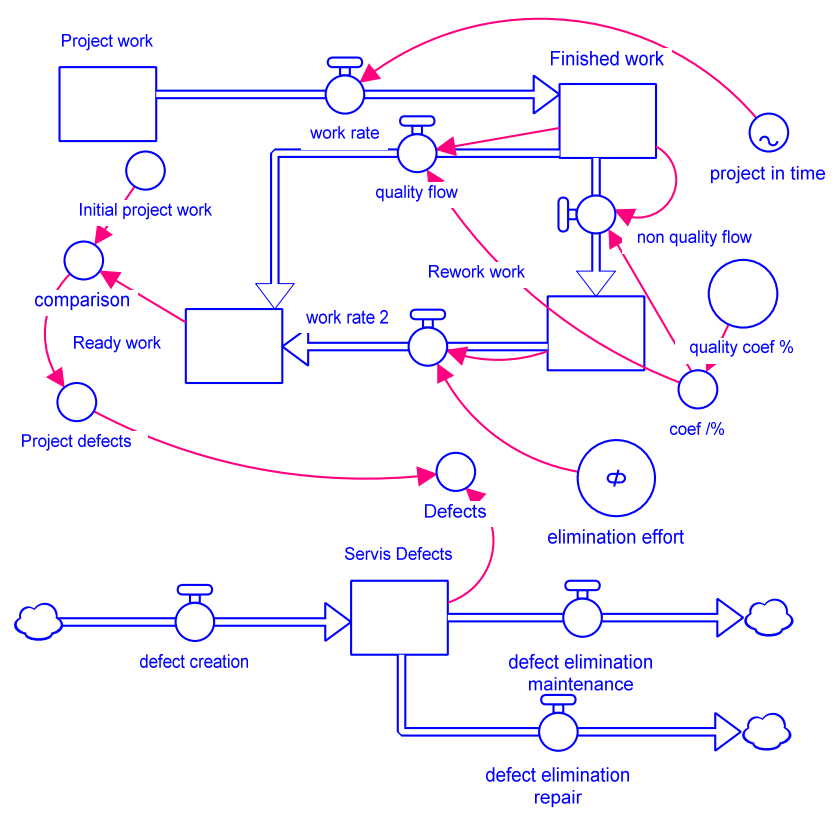

Fig. 2. Model with two main parts. 
Other elements describe the planned maintenance and the corrective maintenance. Full description of this part of the model is in [5]. The key outputs from the model are the amounts of defects named Project defects, Service defects and Defects.

The simulation was performed for 20 years for the office with 10 maintenance workers. The construction period was 3 years. Input values of key parameters are in Table 1 and in Table 2.

Table 1. Input values in the model - project period.

\begin{tabular}{|c|c|c|}
\hline Parameter & Units & Value \\
\hline Quality coefficient & {$[\%]$} & 5 \\
\hline $\begin{array}{c}\text { Elimination defect } \\
\text { time }\end{array}$ & {$[$ month] } & 6 \\
\hline
\end{tabular}

Table 2. Input values in the model - service period.

\begin{tabular}{|c|c|}
\hline Parameter & Value \\
\hline Active worker maintenance & 2 \\
\hline Active worker repair & 3 \\
\hline Available workers & 5 \\
\hline
\end{tabular}

\section{Results}

The resultant values are presented in Figure $3-5$. The time period 20 years includes the construction period and the service period when the building is exploited. The simulation does not consider the last period of the life cycle, wear-out period, when the provided service does not cover our requirements.

The changes in the defect parameter that are created during the construction period are depicted in Figure 3. It is possible to observe the difference between the theoretical end of construction work - Finished work scheduled and Ready work parameters. The level of Ready work for the desired deadline of the project is 67,5 man-year. This is the amount of finished project activities. The reason for the delay is the rework of the project activities that were recognized as low-quality work. In addition, in fact there are two flows - the first one covers the activities that were recognized by the construction company and the second flow is the rework of activities recognized by the investor. For simplification the model uses one flow (in the model it is named work rate 2 ).

Figure 4 describes the changes of the defect parameters that are evoked during the service period and that are eliminated by the planned and corrective maintenance. This time period starts in the third year. In the beginning these activities are done concurrently together with rework activities from the construction period. The shape of the curves is influenced by the availability of the workers who share the time between both kinds of maintenance. The depicted swings are caused by moving maintenance people from the planned activities to the corrective activities and vice-versa.

The sum of defects is presented in Figure 5. The project defects are eliminated during the first months by the construction company. 


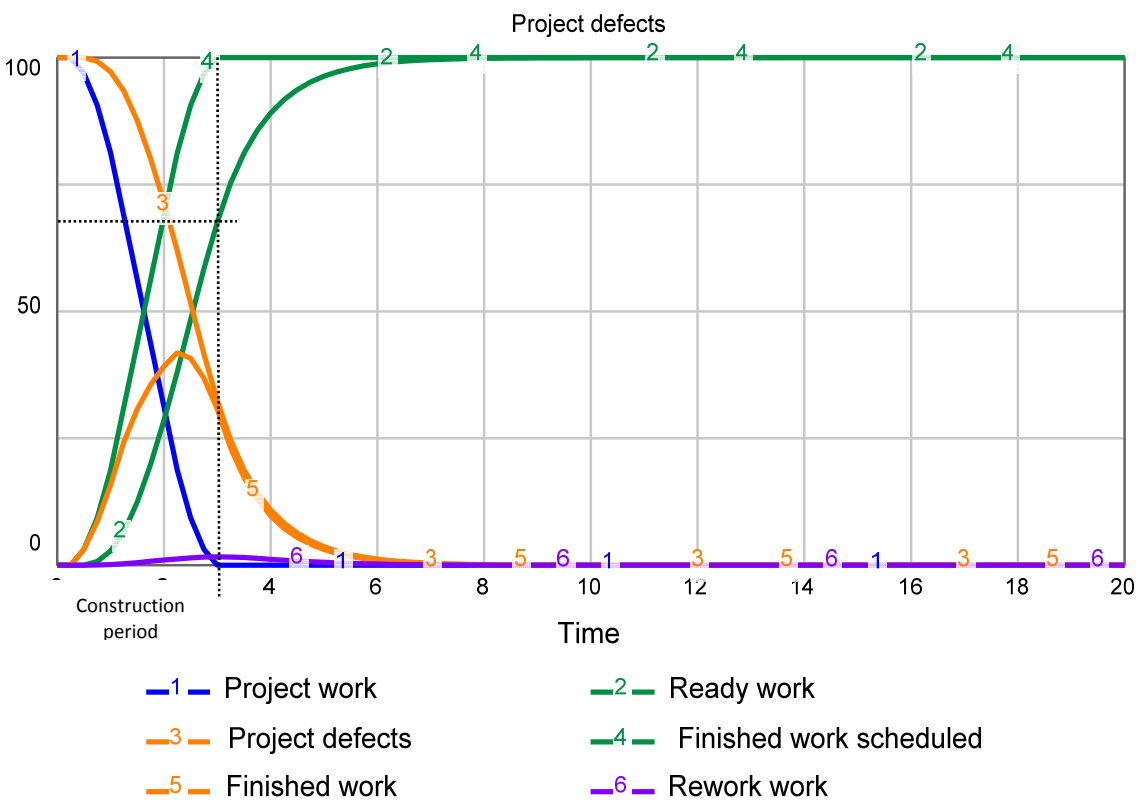

Fig. 3. Project defects during the building life cycle.

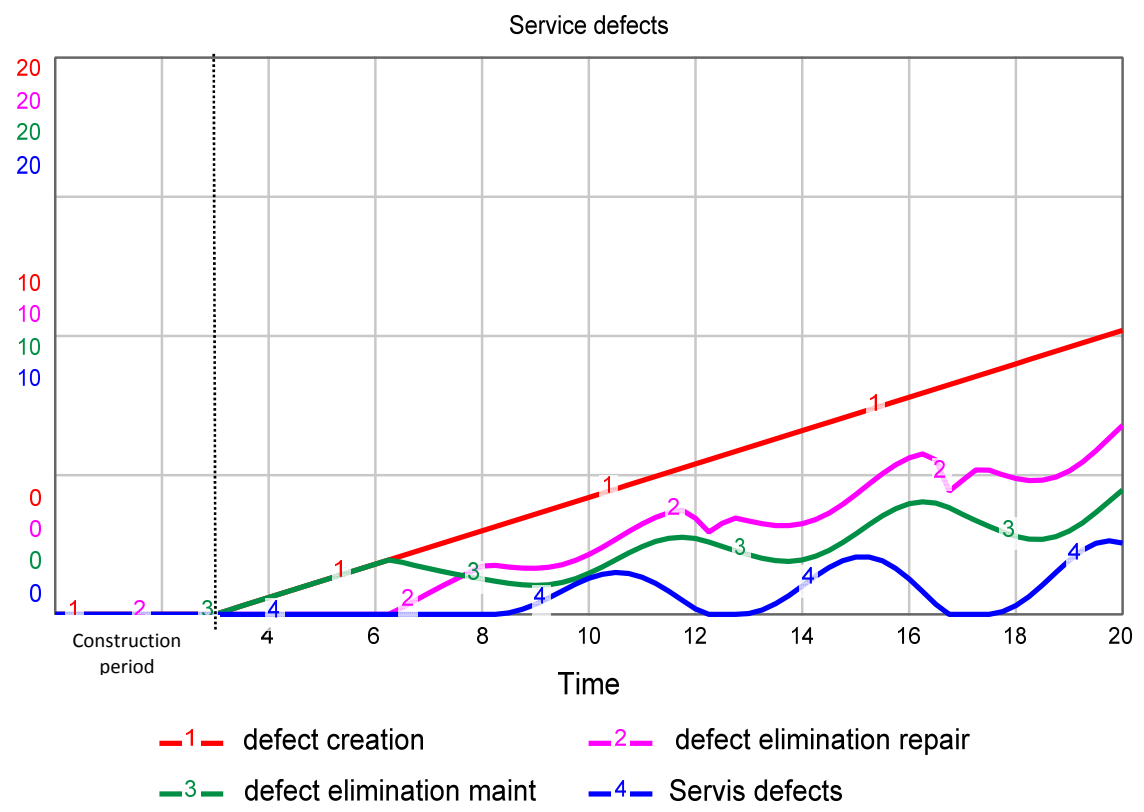

Fig. 4. Service defects during the building life cycle. 


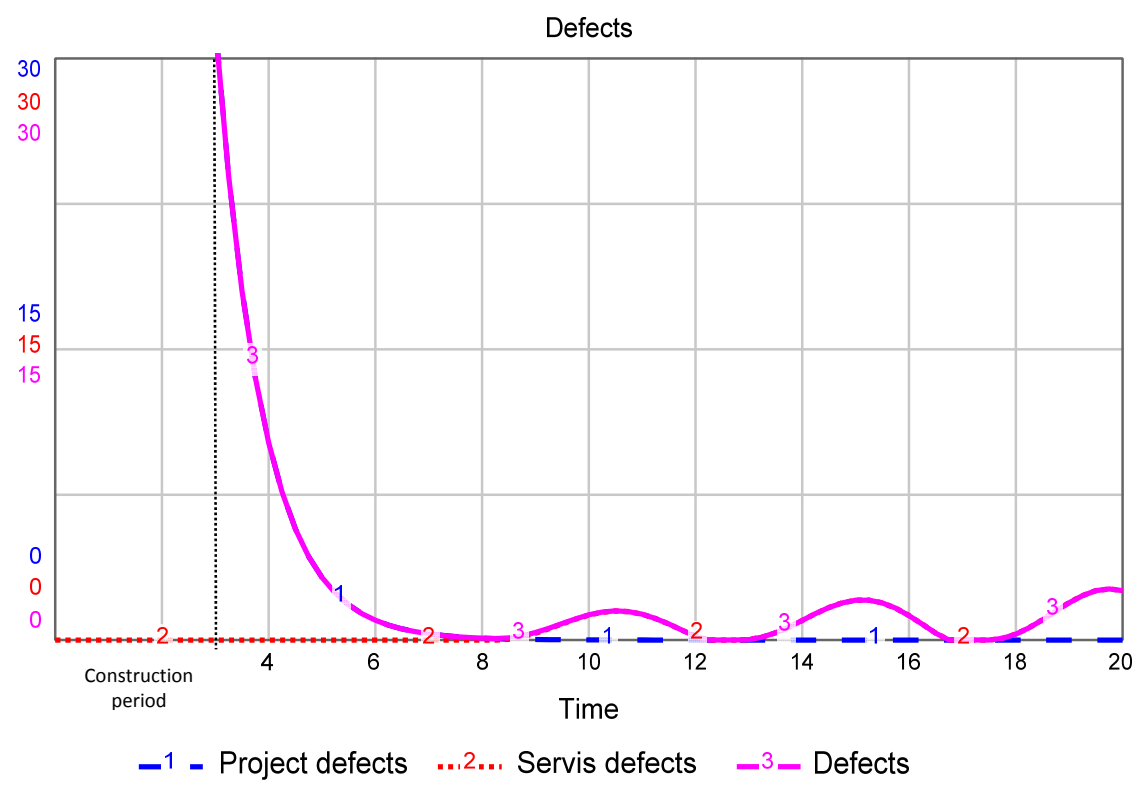

Fig. 5. Project and service defects.

\section{Conclusions}

The model for the description of the main system parameters changes concerning the defects creation and the defect elimination has been developed. The model helps to understand the behaviour of the complex system that covers the project management activities (construction period) and operation management (service period).

Future development will be focused on the modelling of the capacity for the better description of the defect elimination for both subsystems of the model. Another improvement can be expected from the introducing management system for the design of the stable system.

This research has been supported by SGS grant SGS17/122/OHK1/2T/11 Dynamic models of changes in building industry investments.

\section{References}

1. B. Chanter, P. Swallow, Building Maintenance Management (Blackwell Publishing, Oxford, UK, 2007)

2. E. Finch, Facilities Change Management (Willey-Blackewll Publishing, UK, 2012)

3. J.D. Sterman, Business Dynamics: Systems Thinking and Modeling for a Complex World (Irwin/McGraw-Hill, Boston, MA 2000)

4. J. Morecroft, Strategic Modelling and Business Dynamics (Wiley, Chichester, UK, 2008)

5. D. Vytlačil, MATEC Web of Conferences, 146, 01011 (EDP Sciences, 2018) 